\title{
PERSPECTIVAS PARA A ADEQUAÇÃO DE COMPETÊNCIAS NA FORMAÇÃO DO DESIGNER BASEADAS NUMA PROPOSTA PEDAGÓGICA DE DESENVOLVIMENTO SÓCIO-ECONÔMICO
}

\section{PERSPECTIVES TO THE SUITING OF COMPETENCES IN THE CONSTRUCTION OF INDUSTRIAL DESIGN BASED ON THE TEACHING PROPOSAL OF SOCIAL-ECONOMIC DEVELOPMENT}

\author{
Claudelino Martins Dias Junior \\ Administrador e Pesquisador \\ Secretaria Estadual da Saúde de Santa Catarina (SES-SC); Universidade Federal de Santa \\ Catarina (UFSC) e Universidade Nova de Lisboa (UNINOVA) \\ Divisão de Desenvolvimento Organizacional; Doutorando do Programa de Pós-Graduação em \\ Engenharia de Produção e Sistemas (PPGEP) e Instituto de Desenvolvimento de Novas \\ Tecnologias (GRIS) \\ Campus Universitário da Caparica, Residência Universitária Fraústo da Silva, Azinhaga da \\ Chanoca, Costas de Cão - 2825-045 - Portugal \\ Tel.: +351 212948365; e-mails: dias.jr@deps.ufsc.br e/ou cdj@uninova.pt

\section{Marcelo Kammer Faria do Carmo} \\ Professor e Consultor de Gestão de Design \\ Universidade do Oeste de Santa Catarina - Núcleo de Inovação e Design de Embalagens \\ Rua Padre Anchieta, 219 - Xanxerê - CEP 89820-000 - Santa Catarina - Brasil \\ Tel.: 49 3433004; e-mails: marcelo@ unoescxxe.edu.br e/ou mkammer@uol.com.br
}

\section{RESUMO}

O repensar dos conteúdos pedagógicos mais ajustados ao desenvolvimento de competências para o profissional em design deve levar em consideração o fato de que esses mesmos conteúdos têm uma relação de interdependência com outras áreas do conhecimento. Sugerese, então, como base primeira de análise, a proposição de uma concepção do design, consoante uma perspectiva unificadora de conceitos, concebendo o designer tendo em conta as efetivas necessidades de consumo de bens e serviços, bem como a pluralidade de contextos sociais em que esse profissional é demandado. Dessa forma, o novo perfil para o designer deve partir de uma revisão de habilidades a serem desenvolvidas nos cursos de graduação, tendo por objeto formar um profissional não somente interessado em promover o caráter 
estético e funcional de um dado produto, mas, sobretudo, conceber um agente solucionador de demandas externas que esteja apto a interagir com os demais subsistemas sociais.

Palavras-chave: design, designer, competências.

\section{ABSTRACT}

The rethink of the pedagogical contents adjusted to development of abilities for the professional in design, must take in consideration the fact that these same contents nave a relation of interdependence with other areas of knowledge. It is suggerted, then as first base of analysis, the proposal of a conception of design, consonant an unifying perspective of concepts, leading the designer to consider the effective needs of consumption of goods and services, as well as the plurality of social contexts where this professional is demanded, in this way, the new profile for the designer must come from a revision of abilities to be developed in graduation courses, having as object to from a professional, not only interessed in promoting the aesthetic and functional character of a certain product, but, above all, to conceive an agent who will solve the external demand, that is apt to interact with the rest of the social subsystems.

Keywords: design, designer, abilities.

\section{INTRODUÇÃO}

O presente estudo apresenta um levanto das discussões sobre quais definições deram origem ao Design industrial, sabendo-se que a figura desse profissional surge em decorrência do processo de industrialização iniciado no Século XX com a concomitante necessidade de conciliação aos ditames de uma economia alicerçada basicamente no capitalismo dentro de múltiplos contextos sociais. E a partir dessa conciliação de natureza epistemológica, definir o papel destinado ao Designer industrial de forma a desmistificar conflitos de competências com as demais profissões que lhe são congêneres e que subsidiam sua atuação. Outrossim, propõe-se, a partir de uma noção de integralidade e tomando-se por base as conclusões de demais trabalhos acadêmicos, que as diversas áreas do conhecimento (engenharia, administração, estatística, artes) que fomentam conhecimentos específicos à atividade Design, possam permear um novo rol de competências necessárias à formação do Designer e conseqüentemente mais ajustadas aos contextos organizacionais contemporâneos. 


\section{METODOLOGIA}

Utiliza-se uma abordagem indutiva, amparada por revisão bibliográfica do tema. Igualmente, efetua-se uma catalogação de experiências empíricas e teóricas que basilaram a formação e a concepção do profissional em Designer.

\section{A CONCEPÇÃO DO DESIGN INDUSTRIAL CONSOANTE UMA PERSPECTIVA UNIFICADORA}

Entendendo-se necessária a tentativa de unificação de definições surgidas em decorrência da atuação do Design industrial, mesmo que essas careçam de uma uniformidade conceitual, que possam transmitir diretrizes de determinação da função social desse mesmo profissional. Para Maldonado (1999), por Design industrial entende-se a concepção de objetos de fabrico industrial por meio de máquinas, e em série. Pode-se, no entanto, revelar a ambigüidade decorrente dessa definição no que concerne à diferenciação da atividade do engenheiro e do Designer industrial. Não obstante, a definição nos remete a idéia de que todos os objetos não fabricados industrialmente não entram, por conseguinte, no âmbito de atuação do Design industrial.

Conforme Dorfles (1991), para se afirmar que um objeto pertence ao Design industrial há de se considerar as seguintes premissas: o seu caráter de série; produção mecânica; e a presença de um coeficiente estético, estando este último constante no projeto inicial e não a ulterior intervenção manual. Assim, por analogia, os objetos confeccionados antes da Primeira Revolução Industrial não podem ser considerados como uma contribuição originária da figura do Designer industrial.

Segundo a própria definição da ICSID (International Council of Societies of Industrial Design) "o industrial Design é uma atividade criadora cujo fim é determinar as qualidades formais de objetos produzidos industrialmente”. Estas qualidades formais não dizem somente respeito às características exteriores, mas principalmente, às relações de estruturas e funções que transformam um sistema em unidade coerente, tanto do ponto de vista do produtor como do consumidor". De fato, à definição exposta, podem ser acrescidas algumas considerações que explicitam a definição de Design: 
- responder antes de tudo, às necessidades humanas fundamentais, tanto a nível individual, como ao nível da sociedade;

- adaptar o objeto ao homem, e não o homem ao objeto - não agressão das noções (psicologia

e fisiologia);

- primar pelo interesse público em benefício de uma rentabilidade indevida;

- estar consciente do fato de que uma procura do público não confere ao objeto um critério de qualidade;

- conciliar os imperativos técnicos e econômicos, a fim de conceber um objeto acessível a um maior número de consumidores;

- afirmar o acordo entre função, forma e materiais;

- determinar de maneira absoluta a forma e os materiais empregados na industrialização do produto;

- estudar os caracteres estéticos e tecnológicos de um produto industrial, tendo em conta a duração normal de utilização e

- conceber todo o produto de maneira que seu envelhecimento seja provocado por uma evolução tecnológica e funcional, e não por um fenômeno da moda.

Tendo-se em mente este breviário, infere-se a perspectiva de melhor justeza no alcance de objetivos sociais, por meio de uma maior sustentabilidade na atividade de produção (CALÇADA et al, 1993).

Concomitantemente Calçada et al (1993), afirma que é impossível que o projeto do Designer abranja todas as situações potenciais, da tecnologia produtiva mais apropriada a reação do público, passando pela economia da produção e pelas campanhas publicitárias. Assim, o Design não constitui panacéia, mas método e disciplina, sendo: método de concepção, disciplina de realização e produção.

Dentro de abordagem de encaixe de sua contribuição em face de um sistema organizacional concebido a formatação de produtos destinados à futura comercialização, o Design industrial necessita igualmente estar atento às alterações do macro ambiente. No dizer de Maldonado (1999), significa coordenar, integrar e articular todos fatores relativos à produção, à utilização, à fruição e ao consumo individual ou social do produto (funcionais, simbólicos ou culturais). 


\section{A FORMAÇÃO DO DESIGNER TENDO EM CONTA AS EFETIVAS NECESSIDADES DE CONSUMO}

Anteriormente a uma proposição de que tenha em conta produtos concebidos a partir de uma lógica que prime por pressupostos artísticos ou funcionais, as próprias incursões da Bauhaus, através de Van de Velde ou de W. Gropius foram tentativas de adaptação a uma crescente e oscilante máxima capitalista. O Fordismo entrou, num primeiro momento, como pano de fundo para o surgimento de um ambiente de euforia nas primeiras décadas do Século XX, sua abordagem insistia na busca pela maior produtividade, tendo como princípio basilador a simplicidade construtiva e funcional a partir da promessa de longevidade de modelos produzidos (especificamente de automóveis).

Com o aumento da concorrência no ramo automotivo, a apregoada estandardização como resposta a critérios de economicidade, proposta por Henry Ford, cedeu espaço a uma estratégia de diversificação de modelos, através de uma abordagem efetivada a partir da gestão de Alfred Sloan Jr. na General Motors dos anos 20, tendo como pano de fundo a necessidade de remodelagem da concepção de negócios atingidos então pela crise norteamericana de 1929. Surge, a partir de então, uma concepção antifordista onde o styling aparece como principal estratagema na conquista do mercado de consumo.

Para Maldonado (1999), o styling constitui a modalidade de Design industrial que procura tornar o produto superficialmente atraente em detrimento de sua qualidade e conveniência para quem o consome, procurando, outrossim, um envelhecimento artificial, ao invés do prolongamento de sua fruição e utilização. No sentido de encaixar-se a uma perspectiva de ajustamento das demandas provindas de uma visão capitalista, o Designer industrial enveredou para perspectivas utilitaristas e desprovidas de envolvimento social, bem como de consideração dos efeitos econômicos negativos que desta lógica viriam advir. Assim, o styling constituiu uma bizarra resposta à crise e indiretamente assumiu o papel de agente ativo de metabolismo do capitalismo.

De acordo com Calçada et al (1993), podemos definir o Design industrial, que objetiva o cunho de seu trabalho como sendo o styling, o "cosmeticista", sendo o artista que manipula a visão superficial do objeto e que busca artificialmente aspectos diferentes de acordo com a moda ou tentando ditar tendências. A voga do styling e do desperdício nele implícito, suscitou o surgimento de produtos com formas simples e funcionais - como decorrência, defini-se o 
Design "funcionalista", o qual constitui um colaborador decisivo para se encontrar o produto necessário dada uma situação econômica, bem como para a racionalização formal do objeto e não apenas uma forma imaginativa de embalagem para efeitos de venda.

Observa-se, que no vocabulário de um número crescente de empresas de todo mundo o Design passou a significar a totalidade das atividades e competências que recolhem todas as informações relevantes e a transformam em um novo produto ou serviço (LOJACONO e ZACCAI, 2004).

Considerado que o papel do Design está cada vez mais atrelado à consideração de eventos externos a organização, deve-se, necessariamente, buscar-se nesse contexto a perspectiva de remodelamento de seu objeto numa perspectiva endógena, tendo em vista encerrar uma contribuição mais significativa de suas atribuições.

\subsection{O Designer Industrial e a Necessidade de Caracterização de um Novo Perfil}

Segundo Dorfles (1991), o Design na sua fase inicial de projeto consiste em pensar o problema, não considerar a solução a revelia de análise, deve procurar definir se o problema foi colocado com clareza e se torna compreensível para o público a que se dirige. No entanto, sugere que o Designer não deve se colocar a mercê da vontade do produtor e nem tampouco do consumidor, outrossim, deve efetivamente satisfazer os requisitos básicos impostos pela função, pelos custos e pela análise de mercado e possa, além disso, difundir um elemento de "novidade" e como tal educar o público para um novo gênero de linhas e formas que não estava habituado.

Analogamente à concepção de Dorfles, Calçada et al (1993) acredita que a concepção de um produto deve não só incutir a lógica de fabrico, economia e uso, mas também estar integrada a uma lógica de sistemas que a sua utilidade social pressupõe. Desta forma, necessita-se, como diretriz ao exercício da função de Designer, a capacidade de equacionar conflitos entre as necessidades a satisfazer para a vida e os meios de que se dispõe para satisfazer, seja de produtos ou do ambiente.

Maldonado (1999) corroborando a visão de Calçada et al (1993), personifica o papel do Designer como sendo, entre outras coisas, um criativo solucionador de problemas e tendente a ensimesmar essa tendência, necessita conhecer as implicações sociais, econômicas e culturais das realidades emergentes. 
A concepção de um Designer que resultaria do alargamento da visão do Designer "funcionalista" seria o Designer "sistêmico" ou "ecologista". A diferença deste "novo profissional" é não estar limitado ao objeto em si, mas ao seu repensar como componente de sistemas mais vastos, por reconhecer que a simples racionalização tecnológica e formal pode ter como pré-requisito uma irracionalidade do ponto de vista da economia do país, dos interesses reais dos consumidores ou do equilíbrio ecológico ou ambiental (CALÇADA et al, 1993).

Outrossim, o Design constitui uma atividade que envolve uma ampla gama de conhecimentos pertinentes a outras profissões. O termo Designer se refere a um indivíduo que pratica uma profissão intelectual e não simplesmente oferece um negócio ou presta um serviço para as empresas. A própria atividade se caracteriza pela sua natureza interdisciplinar, pois lança mão na sua prática de conhecimento de outros campos de saber, vez que muitos são os fatores envolvidos em um projeto de Design, como: econômicos, sociais, culturais, ambientais, funcionais, estéticos, simbólicos, tecnológicos, e de comunicação (DIAS, 2004).

No sentido de ter sua contribuição aumentada qualitativa e quantitativamente a partir de uma visão sistêmica, faz-se necessária uma constante integração e conseqüente cooperação com diversos outros ramos do conhecimento, no que se refere às ciências sociais aplicadas: as atividades de pesquisa mercadológica; previsões de demanda; observações de comportamentos de compra, e às ciências exatas a relação estreita da possibilidade de desenvolvimento de novas tecnologias dinamizadoras de novas concepções produtivas. Esse processo sinérgico de propulsão de novos conhecimentos deve ser concebido a partir de uma estrutura ágil, flexível e atenta capacidade de resposta às demandas sociais, sendo esta os cursos de graduação que ofereçam um ambiente de ajustamento das qualificações do seu corpo discente mais fidedigno à natureza do profissional de Designer, a partir de um repensar pedagógico.

\section{A IMPORTÂNCIA DA CONTEMPORANEIDADE NAS PROPOSIÇÕES PEDAGÓGICAS PARA O DESIGN}

Para Calçada et al (1993), o Designer deve desempenhar atividades de programação dos sistemas de produção, e igualmente responsabilizar-se por um controle social das prioridades e condicionamentos oriundos do meio, tendo em vista os efeitos sócio- 
econômicos. Assim, parte-se ainda de alguns pressupostos para a formação no campo do Design que devam ser observados, quais sejam:

- requer uma fórmula clara de ensino-investigação que produza Design e respectivas bases críticas, para tanto formar-se solucionadores de problemas e

- não criar-se "escolas de Design industrial", correndo o risco de apartar a concepção de produtos do seu contexto ambiental e econômico-social, isolando-a da co-presença de outras escolas e fatos do ambiente.

$\mathrm{Na}$ consideração de quais seriam as prerrogativas necessárias ao estabelecimento de uma grade curricular pedagógica, que permeie o desenvolvimento de competências para o melhor ajuste do perfil profissional de Design, há que se levar em consideração experiências pregressas que, da mesma forma, basilaram a formação dos desses mesmos profissionais que agora respondem por este repensar de coisas.

\subsection{ESDI - Uma Experiência Pedagógica Brasileira}

A experiência da ESDI (Escola Superior de Design Industrial) do Rio de Janeiro, que no findar da década de 60, já concebia, através de suas assembléias deliberativas, diretrizes norteadoras da atividade do Designer industrial, observava as discrepâncias decorrentes do ambiente, que constituíam elemento comprometedor do pleno desenvolvimento da nova profissão. Pertinente se faz a consideração da natureza de condicionantes que eram colocadas como sendo as principais limitantes à formação do Designer industrial no país, destacando:

- a atividade de ensino defrontava-se com um mercado em recessão, refratário ao investimento na inovação e prestes a ser entregue a uma exploração livre e desenfreada pelo capital externo, por sua potencialidade de consumo e incapacidade de atendimento pela estrutura produtiva nacional. Por isso, o lema: "atuar no e sobre o mercado", significou o fim de uma visão utópica e o início de um processo igualmente utópico de se repensar o Design;

- a ESDI ao contrário da experiência de $H f G$-Ulm, onde foi necessária a revalorização do projeto devido ao forte peso da teoria, valorizou o projeto em detrimento da teoria. Essa a atitude, não obstante, prejudicou esforços de adequação, sendo que todos os encaminhamentos se deram a partir de discussões e interpretações pessoais e, por conseguinte imprecisas e

- verificou-se que a mudança no currículo dessa escola deveria ter sido efetuada não a partir de si, mas da consideração das conclusões extraídas dos últimos trabalhos de pesquisa dos 
últimos semestre, que deixaram evidências claras de como o profissional deveria atuar no mercado e quais seriam suas limitações (SOUZA, 1996).

Evidencia-se com o exposto, a perspectiva de formação do Designer como agente de resolução de problemas. Dessa forma, a escola moderna deveria ter como bases metodológicas: a análise de sistemas, a investigação operacional e a teoria probabilística da decisão, bem como a consideração de métodos não-sistemáticos para o desenvolvimento da criatividade em grupos psicologicamente motivados. Parece, agora, que a formação de "Designers para o ambiente" processar-se-á no nível de formação universitária e dentro de uma faculdade, não isolada das outras, permitindo-se opções graduais a partir de um tronco comum entre campos de especializações (CALÇADA et al, 1993).

\subsection{A Busca de Ajuste Pedagógico para a Formatação de um Novo Perfil Profissional}

Design deve estar alicerçada numa proposição que integre a prática e a teoria, através da implantação de laboratórios de Design que objetivem fornecer uma relação entre o perfil profissional e os conteúdos teóricos ministrados constantes na grade curricular devem considerar sua conformidade com as Diretrizes Educacionais para o Ensino do Design.

Entrementes as considerações expostas, para Dias (2004) o cerne na materialização de uma proposta pedagógica para o profissional em Design, seria: "Quais as diferentes relações e conexões que podem ocorrer entre as diversas disciplinas ou áreas do conhecimento que envolvam a disciplina de Projeto de Produto?".

Considerando as disciplinas que devem constar no Núcleo Básico Comum (Obrigatório Fixo) definido pelo MEC para os cursos de Design, e ressaltada a importância do questionamento de Dias (2004), fica clara a necessidade de inserir-se a disciplina de Projeto de Produto como espinha dorsal do curso de Design, justificada pela sua importância em permitir a união teórico-prática em um único mote de conhecimentos. Observa-se, que a escolha das disciplinas constantes da Habilitação (conteúdo Obrigatório Variável) devem se dar a partir de critérios de interdisciplinaridade cruzada (determina o que as demais disciplinas deverão assumir, como axiomas, conceitos, métodos e marcos teóricos) e interdisciplinaridade (estruturas conceituais e metodológicas afins com unidades globais).

Não obstante, para a definição da Ênfase (conteúdo Optativo) deve-se levar em conta a vocação institucional em consonância com as atividades de produção presentes no entorno das 
instituições de ensino. Constituindo, assim, marcos para redefinição das competências do Designer.

\section{DETERMINAÇÃO DE COMPETÊNCIAS DO DESIGNER EM RELAÇÃO AOS NÍVEIS DE PROFICIÊNCIA DISCIPLINAR}

Sendo a atividade do Designer permeada por um objetivo, implica-se dizer que para a efetiva concretização desse mesmo objetivo a perspectiva de integração com um sistema de ações intermediárias, cada qual com objetivos parciais, que por sua vez viabilizaram um conjunto de operações menores (Dias, 2004). Dada a necessidade de concretização dessas operações menores e de ações intermediárias, são necessárias competências a serem desenvolvidas a partir da determinação de habilidades mentais e motoras que sejam desenvolvidas a partir de uma grade curricular pedagógica ajustada a demandas sociais. Tal abordagem é representada em Figura 1.

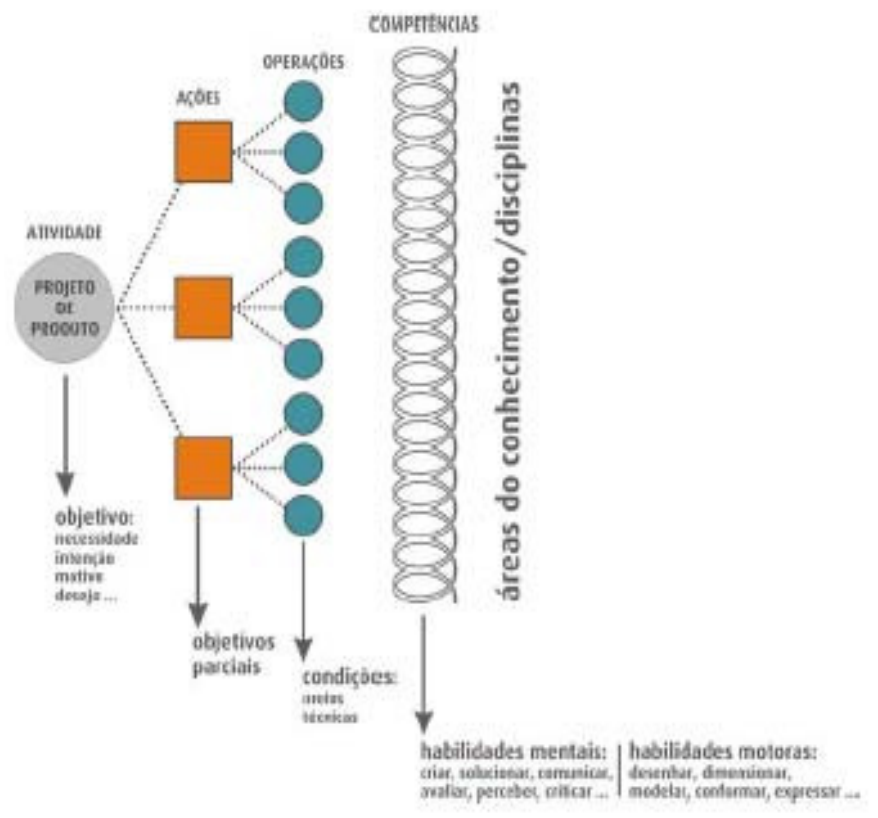

Figura 1 - Atividade de Design, ações, operações e competências - Interdisciplinaridade na disciplina de projeto em Design. (DIAS, 2004, p. 120)

As competências do Designer são configuradas a partir de uma dinâmica de interação de áreas de conhecimentos congêneres, elegendo-se disciplinas que permeiem o objeto tronco da grade curricular (Projeto de Produto), que conseqüentemente encerra o valor de percepção 
que o mercado elege como sendo prioritário na contratação do profissional. Há que se observar, no entanto, essas mesmas competências só poderão ser passíveis de uma avaliação mais objetiva, quando da definição dos níveis ótimos de proficiência necessária para o desenvolvimento de habilidades mentais e motoras (ver Figura 1).

De acordo com Santos (2000), cada competência pode ser exercida em níveis de proficiência distintos, propõe-se, então, uma classificação de competências no sentido de orientar a ação de readequação dos cursos de graduação. Sendo essa classificação de competências, como: técnicas (habilidades técnicas específicas da área); funcionais (habilidades relacionadas ao negócio); gerenciais (habilidades de gestão de pessoas e recursos); comportamentais (condicionamentos pessoais e culturais). Está abordagem pode estabelecer uma ordem de categorização, a partir da qual serão mensurados os níveis de proficiência necessários aos egressos dos cursos de graduação em Design, tendo em conta ainda as devidas habilitações pertinentes.

\section{CONCLUSÃO}

A própria dificuldade dos profissionais em Design em definir claramente as ramificações decorrentes da sua atividade, enseja-se no fato de não se ter uma definição devidamente esclarecedora que se transponha de maneira uniforme ao conhecimento público. Igualmente, consoante um breve histórico das escolas que procuraram definir uma identidade para o Designer, observa-se que estas pecam por impor ideologias que tinham como pano de fundo vislumbrar ajustamentos com uma vacilante trajetória do capitalismo.

Procurando-se traçar prerrogativas à definição de um perfil mais ajustado para o Designer, no qual possa estar evidenciada sua efetiva contribuição no contexto social, notabiliza-se a importância de uma visão voltada para as reais características sócio-culturais do meio, onde o papel dos cursos universitários destinados à formação de Designers deva, necessariamente, primar por uma visão integralizadora da atividade, desenvolvendo uma natureza multidisciplinar de competências necessárias ao atendimento do objetivo último destes profissionais - formatação de projetos, com horizontes totalizantes para atividade de produção de bens e serviços. Atentando-se ao fato de que a atividade de Design surgiu da necessidade de atendimento das necessidades da indústria em novos formatos, que visualizava maiores ganhos a partir da identificação/criação de diferentes demandas de mercado (multiplicidade de modelos e de perspectivas estéticas de produtos). 
Consoante o exposto, sugere-se que o ajustamento do perfil profissional do Designer deve levar em consideração a interação pedagógica constante com outras áreas do conhecimento que o subsidiem com a instrumentalização de competências-chave, no sentido de oportunizar seu balizamento profissional dentro de contextos sociais ávidos por resoluções de problemas ligados a melhor concepção e condução de estruturas de produção.

\section{REFERÊNCIAS BIBLIOGRÁFICAS}

CALÇADA et al, Ana. Design em aberto, uma antologia. Coleção "Design, Tecnologia e Gestão”. Tradução: Pedro Afonso Dias. Portugal: Bloco Gráfico, 1993, Lda., 256p.

DIAS, Maria Regina A. C. O Ensino do Design: a interdisciplinaridade na disciplina de projeto em Design. Dissertação de Mestrado. Programa de Pós-Graduação em Engenharia de Produção - Universidade Federal de Santa Catarina, 2004, 176p.

DORFLES, Gillo. O Design industrial e sua estética. Tradução: Wanda Ramos. Lisboa: Capelli Editora, 1991, $3^{a}$ Edição, 149p.

FONTOURA, Antônio Martiniano. EdaDe - A educação de crianças e jovens através do Design. Tese de Doutorado. Programa de Pós-Graduação em Engenharia de Produção Universidade Federal de Santa Catarina, 2002, 357p.

KELLEY, Tom; LITTMAN, Jonathan. A arte da inovação - lições de criatividade da IDEO, a maior empresa norte-americana de Design. Tradução: Maria Claudia Lopes. São Paulo: Editora Futura, 2001, 341p.

LOJACONO, Gabriella; ZACCAI, Gianfranco. HSM Management - A empresa focada no Design. São Paulo: HSM do Brasil, número 47, ano 8, abril-2004, volume 6, p. 98 - 101 e $104-106$.

MALDONADO, Tomás. Design industrial. Tradução: José Francisco Espadeiro Martins. Portugal: Edições 70, 1999, Lda, 127p.

PROGRAMA DE PÓS-GRADUAÇÃO EM DESIGN. Arcos. Design, cultura material e visualidade. Escola Superior de Desenho Industrial da Universidade do Estado do Rio de Janeiro, 1999, v. II, volume único, 148p.

SANTOS, Neri dos. Gestão do conhecimento. Programa de Pós-Graduação em Engenharia de Produção - Universidade Federal de Santa Catarina, 2000.

SCHIRIGATTI, Elisângela L. Laboratório de Design: o Designer e o mercado de trabalho na era do consumidor. Dissertação de Mestrado. Programa de Pós-Graduação em Engenharia de Produção - Universidade Federal de Santa Catarina, 2002, 108p.

SOUZA, Pedro Luiz Pereira de. ESDI - biografia de uma idéia. Rio de Janeiro: Editora da 
Universidade do Rio de Janeiro, 1996, 327p. 